\title{
Mapping The Drowned World
}

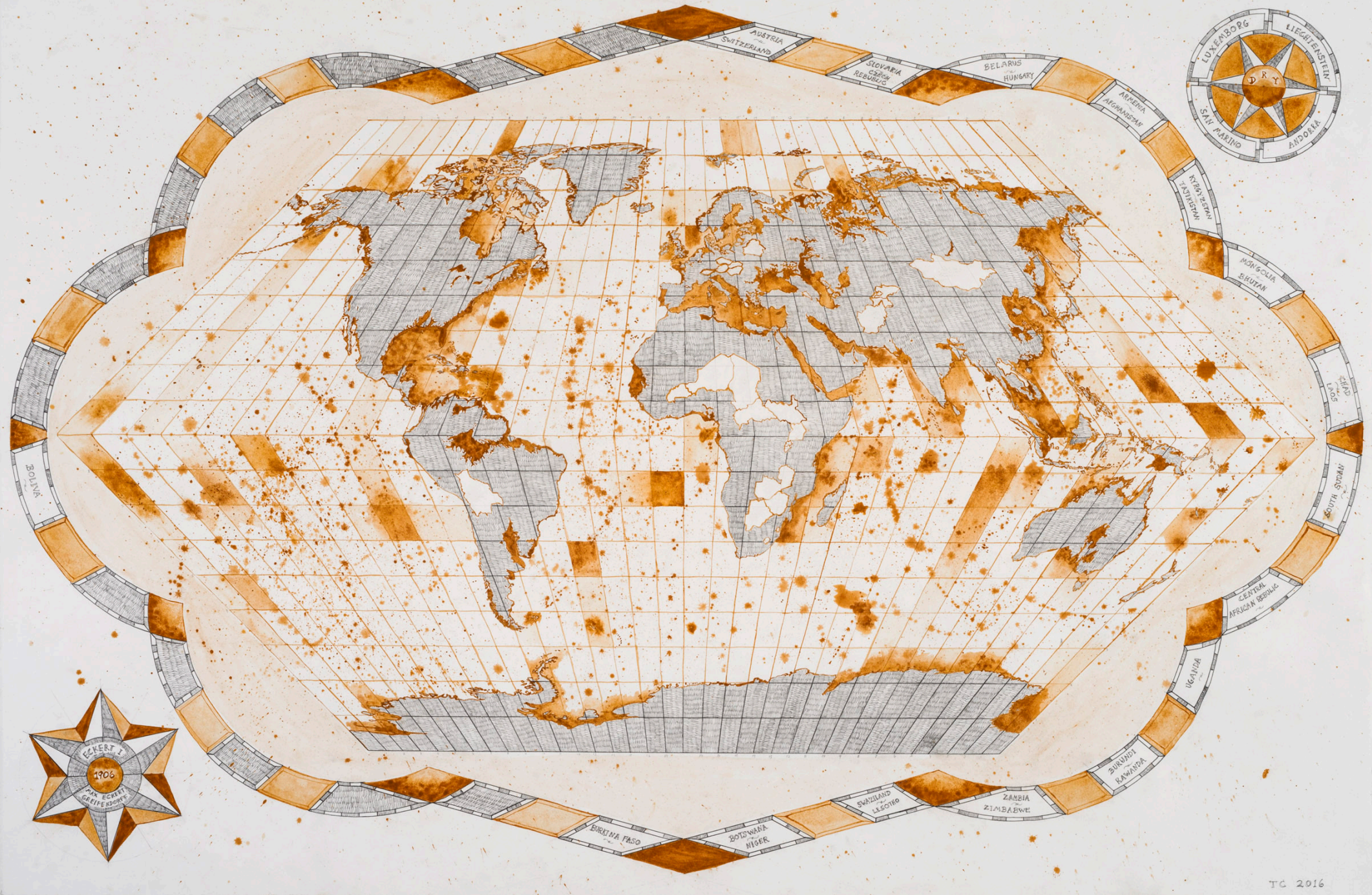

Tracey Clement, Drowned World: Eckert Projection, 2016, pencil and rust on paper, 47.5in x 31.5in.

My Drowned World maps are part of a broader creative project inspired by J. G. Ballard's 1962 book, The Drowned World. In this slim science fiction novel, Ballard presents vivid, startling and disturbing post-apocalyptic imagery of a submerged city, strangled by vines and patrolled by carnivorous reptiles. Written during the perpetual slow-burning crisis of the Cold War, Ballard was responding to the fears of his age. Maps are artifacts deeply embedded in the cultures that make them and the conditions of their time, and my Drowned World maps chart the anxieties of our current crisis: climate change.

In this series of drawings I have represented an ocean level rise of 70 meters (approximately 230 feet) on five different world map projections: Petermann Star, Eckert (I), Bonne, Fuller, and Loximuthal. The figure of 70 meters 
is speculative and is not based on a specific study. My artworks picture planetary geography re-shaped in ways that echo Ballard's post-apocalyptic vision, but they are also grounded in the real: ocean levels are already rising.

Each Drowned World map focuses attention on particular landmasses. For example, in both Drowned World: Bonne Projection, 2015, and Drowned World: Eckert Projection, 2016, Africa is dead center, dwarfing both Europe and North America; this offers a much more accurate, and politically potent, representation of its actual landmass than is found on many other maps.

Maps are not neutral. They are always staking a claim or making a point. In addition to drawing on the narrative potential culturally embedded in cartography, my Drowned World maps also make use of the conceptual weight inherent in materials and processes.
The material used to paint to these maps is ferric oxide, otherwise known as rust. Made from iron, a naturally occurring mineral that has been ripped from the earth, smelted, extruded, and oxidized, rust is symbolic of the widespread human attitude that nature is simply a resource to be exploited. When the rusty oceans of these drawings encroach onto land, we are asked to face our own complicity in creating climate change.

In some of my drawings a graphite pencil is used to "drown" the world instead of rust. The effect is similar, but in these instances it is the action of drawing rather than the qualities of the material that carries the weight of the message. The cross-hatched nature of the pencil marks is clearly labor-intensive. It literally takes dozens of hours to "drown" the world in this way.

In fact, both the painting and the drawing are very labor-intensive. The time-consuming nature of my Drowned

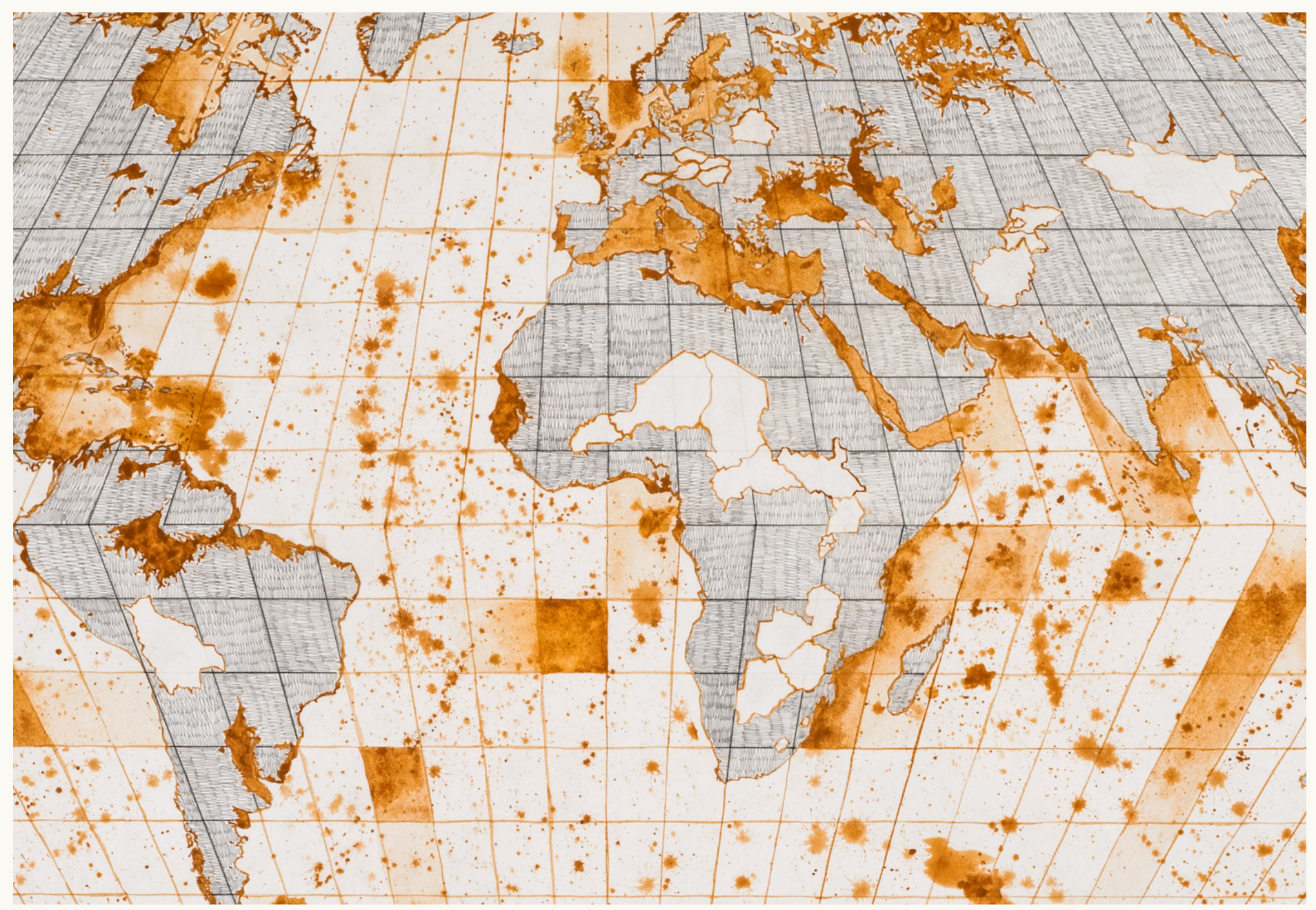



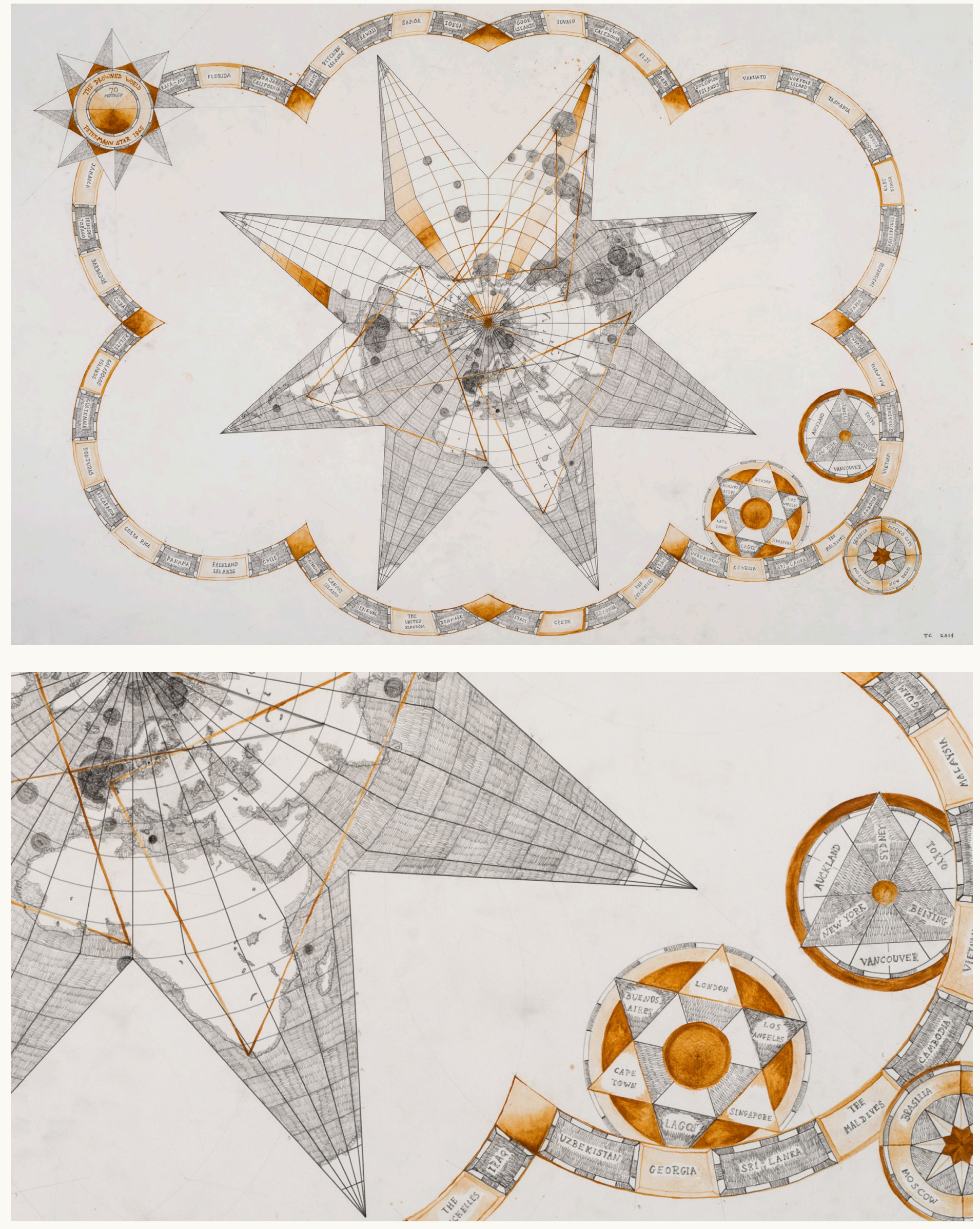

Tracey Clement, Drowned World: Petermann Star (plus detail), 2014, pencil and rust on paper, 47.5in x 31.5in. 

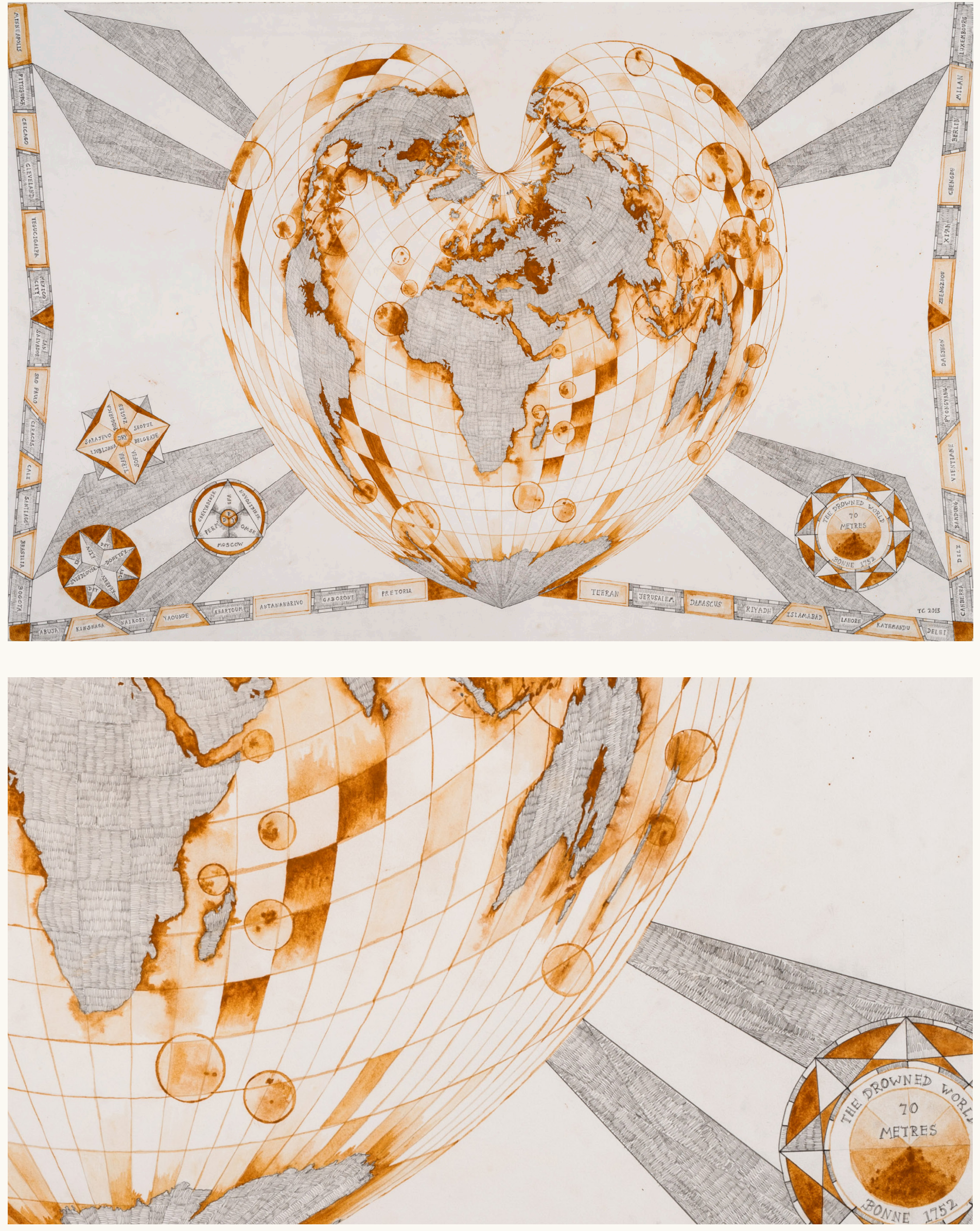

Tracey Clement, Drowned World: Bonne Projection (plus detail), 2015, pencil and rust on paper, 47.5in × 31.5in. 
World maps is a deliberate strategy. Our current crisis did not just happen: it took centuries of dedicated labor, ruthless exploitation of the natural environment, manic consumerism, and blatant disregard for the consequences of our actions to reach this moment in time.

Tracey Clement is an artist, arts writer, and Ph.D. candidate in Fine Art at the University of Sydney. Her current research responds to J. G. Ballard's novel, The Drowned World, with a particular focus on imagery of the ruined city. Clement has exhibited widely, both in Australia and overseas, and her writing is published regularly in numerous art and design magazines.

\section{WATCH TRACEY CLEMENT WORK}

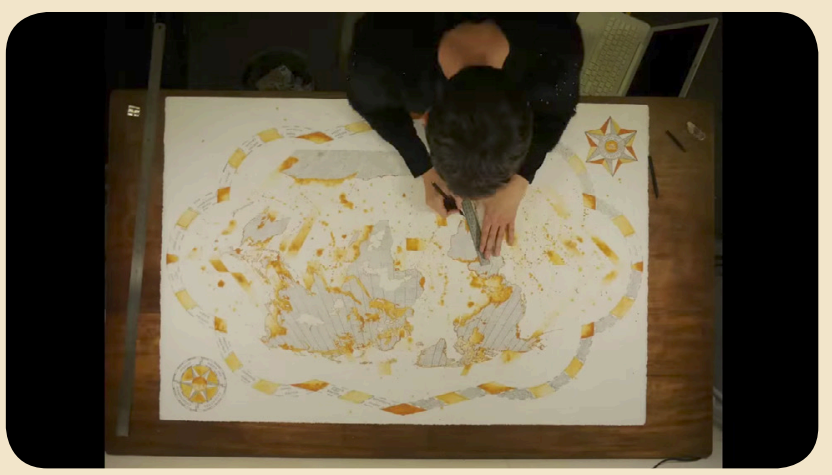

Click to watch, or visit

youtu.be/q0IGighJwbI

\section{LINKS}

\section{Website}

traceyclement.com

\section{Mapping The Drowned World Project}

traceyclement.com/category/mapping-the-drowned-world

\section{Drowned World Maps}

traceyclement.com/category/drowned-world-maps 